\title{
"Pioneros de un nuevo mundo". El discurso de investidura del presidente argentino Mauricio Macri
}

Mariano Dagatti ${ }^{12^{*}}$

\begin{abstract}
Resumen: Este artículo presenta resultados parciales de una investigación de mayor alcance acerca de la construcción de hegemonía discursiva y de identidades políticas en la Argentina contemporánea. Su objetivo general es indagar la configuración del espacio discursivo del actual partido de gobierno nacional "Cambiemos", tomando en cuenta diferentes géneros de comunicación y acontecimientos mediáticos de su primer bienio de gestión. Considerando la perspectiva de la Retórica Constitutiva, el objetivo específico de este trabajo es analizar la estructura fundacional del discurso de asunción presidencial de Mauricio Macri ante el Congreso de la Nación, el 10 de diciembre de 2015. Interesa indagar cómo dicha alocución apuesta a constituir un mundo ético democrático moderno, común a todos los argentinos, a pesar de sus diversas filiaciones políticas, sociales y culturales. La respuesta implica, de manera central, analizar los clivajes que organizan la pars destruens y la pars construens de su discurso. Éstos dejan entrever a tisbos de una hermenéutica histórica que colocaría a "Cambiemos" como el pionero de una nueva cultura política, adaptada a las características del siglo XXI y basada en el trabajo en equipo y el respeto de la unión en diversidad.
\end{abstract}

Palabras-clave: coalición cambiemos; retorica constitutiva; discurso inaugural; hermenéutica histórica.

Abstract: This paper summarizes some key results of an in-depth research
on the building of a discursive hegemony and the construction of politi-
cal identities in contemporary Argentina. The field we have been research-
ing more recently is the discourse realm of "Cambiemos", the coalition of
old traditional and brand-new political parties currently in office. We have
conducted more detailed research of the choice and use of communication
genres and media events by "Cambiemos" until midterm elections. From
the vantage point of Constitutive Rhetoric, we have chosen as a key piece
in the new Government ways of addressing the nation President Macris's
Inauguration Speak in Congress, December 10th, 2015. As befits the man-

1 CONICET/UNQ - UBA.

2 Reconocimientos: Este artículo es el resultado de mi trabajo como becario posdoctoral y actualmente como investigador del Consejo Nacional de Investigaciones Científicas y Técnicas (CONICET) del Ministerio de Ciencia y Tecnología de la República Argentina. Agradezco al organismo porque sin su financiamiento mi formación se hubiera visto notoriamente perjudicada. Al respecto no quisiera dejar de mencionar la preocupación ante los severos recortes presupuestarios del que este organismo ha sido objeto bajo el programa del actual gobierno. Tampoco quisiera dejar pasar la indignante persecución, del todo incoherente con la idea de una Argentina moderna, de la que hemos sido objeto los científicos y becarios de CONICET por parte de diferentes actores gubernamentales y mediáticos, como respuesta a nuestros reclamos sobre la nueva orientación del principal organismo de ciencia y tecnología de nuestro país. Por último, no puedo dejar de mencionar que, mientras termino este texto, se cumplen cuarenta días de la desaparición forzada de Santiago Maldonado. Es responsabilidad indeclinable del Estado argentino su aparición con vida. 
date due to a coalition and not to a single party, the new President emphasized coalitional and pluralist 'modern' values useful to avoid conflict and to unite the constituency, despite diverse political, social and cultural affiliations, in a management, teamwork, context-free ethical standpoint. We discriminated in his injunction to Congress the dualist structure of an agenda built upon the clear-cut opposition of what to do and what to leave behind, the pars destruens and the pars construens of the speech.

Keywords: coalition cambiemos; constitutive rhetoric; inaugural speak; historical hermeneutic.

\section{Introducción}

“Cambiemos" es la coalición política que gobierna actualmente la República Argentina. La alianza está conducida por el partido Propuesta Republicana (PRO), cuyo dirigente máximo es el hoy Presidente de la Nación Mauricio Macri. Está integrada además, entre sus principales miembros, por la Unión Cívica Radical y por la Coalición Cívica-ARI. Organizada en torno de actores provenientes mayoritariamente, aunque no de forma exclusiva, de diferentes tradiciones de la derecha argentina y de viejos y nuevos políticos, gerentes y empresarios, cuya extracción varía entre ONGs, agrupaciones religiosas y empresas de variadas ramas, "Cambiemos" se constituyó progresivamente como la contracara del kirchnerismo, partido de gobierno durante doce años (2003-2015), liderado por los ex presidentes Néstor Kirchner (2003-2007) y Cristina Fernández de Kirchner (2007-2015), con el propósito explícito de movilizar electores, ideas y recursos de grupos sociales y políticos que veían en dicha administración su peor enemigo, el menor de sus beneficios o el mayor de sus males. ${ }^{3}$

Este artículo presenta los resultados de una investigación en curso acerca de la construcción de hegemonía discursiva en la Argentina contemporánea. Su objetivo es indagar una formación política, "Cambiemos", que, surgida en el contexto de mutación del campo político argentino de principios de siglo, ha logrado constituir un espacio discursivo ${ }^{4}$ dominante, capaz de dar respuesta o prometer soluciones a algunos de los problemas que ésta había inicial o residualmente planteado. Con ese fin, interesa describir cómo esta formación organizó desde el Poder Ejecutivo Nacional una retórica fundacional, de corte radical con el pasado reciente, que le permitió establecer una posición de identificación plausible de redefinir el campo en el que se había originado.

Considerando la perspectiva de la Retórica Constitutiva ${ }^{5}$, el objetivo específico de este trabajo es analizar la estructura fundacional del discurso de asunción presidencial de

3 Sobre las características integrales del PRO y del horizonte ideológico, sociológico y político que organiza el programa de "Cambiemos", véase Vommaro, Morresi y Bellotti, 2015.

4 La noción de "espacio discursivo" está inspirada en la de Maingueneau (1983). Introducida conjuntamente con las de universo discursivo y campo discursivo, esta noción no carece de relaciones con la teoría de campos de P. Bourdieu. Debe ser entendida como un subconjunto de un campo discursivo. A diferencia de Maingueneau, no la entendemos como constituida por dos posicionamientos discursivos, sino como un posicionamiento discursivo que puede ser dominante o dominado, central o periférico, en un juego de equilibrio inestable, que es el del campo discursivo, y más en general, el del universo discursivo de una coyuntura dada.

5 El término "Retórica constitutiva" fue retomado y difundido por el académico canadiense Maurice Charland, quien focaliza la noción de identificación como término clave para la retórica. Véase al respecto Charland, 1986; Anderson, 2006; Bruner, 2002. Para un resumen de esta perspectiva retórica, remitimos a Vitale y Dagatti (2015). 
Mauricio Macri ante el Congreso de la Nación, el 10 de diciembre de 2015 (en adelante, DIM). Se trata de indagar cómo dichaalocución de investiduraapuesta a constituiruna frontera política por la vía de la retórica; o mejor dicho, cómo intenta performar un pueblo democrático moderno a partir de un auditorio heterogéneo, compuesto por diversas filiaciones políticas y culturales. La respuesta implica, de manera central, analizar los clivajes que organizan la pars destruensy la pars construens de su discurso. Éstos condensan los prolegómenos de una "hermenéutica histórica" (Angenot, 2008), que es la cristalización (y a su vez re-producción) de mundos sociales de pertenencia, de tradiciones partidarias y de ideologías grupales más amplias 6 .

La elección del DIM como corpus de trabajo responde a dos criterios teórico-metodológicos: el de genericidad, que responde a los lineamientos globales de nuestra investigación ${ }^{7}$, y el de ejemplaridad, que responde a las características del discurso de asunción como pieza paradigmática para estudiar un caso de retórica constitutiva. En primer lugar, el discurso seleccionado nos permite trabajar con un género discursivo típico del campo político, cuyas características pueden definirse con relativa facilidad a partir del estado del arte. En segundo lugar, resulta una pieza ejemplar de retórica constitutiva, debido a que, por razones discursivas e institucionales, opera como un momento privilegiado de la puesta en escena de la performación política.

El artículo se organiza de la siguiente manera. La primera sección está dedicada a describir las características del discurso inaugural como género, con el fin de avanzar luego en un estudio del caso. La segunda parte, la principal (sección II.A), presenta un análisis de los principales clivajes del DIM, entendidos como procedimientos orientados a generar una frontera con el pasado reciente y a celebrar la apertura de un horizonte de felicidad social, ligada de manera estrecha a las soluciones que la nueva administración programa y promete. Señalamos tres clivajes organizadores de toda la pieza: verdad / mentira, líder / equipo, unión / enfrentamiento. Intentaremos demostrar enseguida cómo dichos clivajes se articulan en un clivaje principal: el de la Argentina del siglo XXI versus la Argentina del pasado. La tercera sección (sección II.B) se detiene en la "zona" programática del DIM, tomando en cuenta los tres ejes que el propio orador manifestaría como centrales: «pobreza cero, vencer el narcotráfico y unión de los argentinos». Entramado en buena medida con los clivajes antes trabajados, intentamos demostrar el peso de la unión como núcleo irradiante de la pieza oratoria, cuyo corolario es la solicitud de confianza. El tramo final del artículo (sección II.C) está dedicado a la peroratio del DIM, con el fin de exponer las dos operaciones discursivas que concluyen la alocución: la recapitulación del mensaje central del DIM y la puesta en escena del ethos del orador como garante del proyecto.

\section{Discursos inaugurales: cuestiones de género}

El carácter performativo del lenguaje constituye uno de las conclusiones destacadas de los estudios retóricos. Sabemos, a partir de la definición misma de la Retórica que brinda

6 Estas apreciaciones tienen en cuenta la definición de "identidad política" que brinda Aboy Carlés (2001) y la de "mundos sociales de pertenencia" que brinda Vommaro (2015).

7 Nuestra investigación tiene como finalidad el estudio de la construcción de hegemonía discursiva en el campo político, desde la perspectiva de la teoría del discurso social (Angenot, 1989, 2008, 2010). La problemática que se pretende indagar es la relación entre hegemonía discursiva, identidades políticas y medios de comunicación. Para ello, se ha decidido indagar, inicialmente, los principales géneros discursivos de la política en el bienio 2015-2016, e. g. discursos orales monologales en actos multitudinarios, cadenas nacionales, discursos de efemérides. 
Aristóteles como la facultad de ver en cada caso los medios aptos para persuadir (2005: 43), que el efecto buscado en los destinatarios es sustancial para investigar su condición de acontecimiento oratorio. Griegos y romanos comprendieron tempranamente, en sus indagaciones retóricas, la capacidad pragmática del lenguaje (López Eire, 2002, 2005a y b; Pernot, 2013), el poder de las palabras para hacer cosas en el ámbito político y social e influir en los ciudadanos mediante argumentos más bien psicológicos (ethos y pathos) que lógicos (logos).

En los tiempos actuales la denominada "Retórica constitutiva" ha puesto el acento, en su lectura de la tradición clásica y moderna, en este poder performativo de la palabra, a partir del fenómeno de identificación, tematizado con diferentes matices pero similar enjundia, por K. Burke (1969) y L. Althusser (1988). La idea central de este enfoque retórico es, según M. Charland (1987), que las audiencias son construidas por el discurso, lo que implica examinar como efecto retórico lo que Althusser ubica como el proceso clave de la ideología: la constitución de un sujeto. Así, el discurso fabrica mundos, es, por decirlo con B. Cassin (2008: 72), "demiúrgico".

Los discursos inaugurales o de investidura ${ }^{8}$ conforman un género paradigmático de la oratoria política para estudiar el poder performativo del lenguaje, ya que son instancias institucionales en las que el presidente electo asume el cargo de Jefe de Estado que ha ganado por elección popular. Ofician como "rituales de transición en los cuales el pacto entre la ciudadanía y sus líderes es renovado" y representan, por antonomasia, "una celebración del cambio y la continuidad democráticos" (Kohrs Campbell \& Hall Jamieson, 2008: 29-30) ${ }^{9}$. En virtud de su condición de discurso instituyente, es decir por su predisposición genérica a sugerir fronteras más o menos enfáticas con la administración anterior y herencias ostensibles con las grandes sagas patrióticas, permiten indagar de manera pormenorizada los procedimientos de constitución de una comunidad nacional como entidad imaginaria del discurso político.

Estas alocuciones están destinadas de manera amplia a todos los ciudadanos del territorio nacional. Presentan una dimensión epidíctica ${ }^{10}$, orientada, eminentemente, a celebrar valores compartidos y aponer en escena el pacto entre el nuevo mandatario y la audiencia. Más aún, conectan, debido a su estatuto genérico, en ceremonias rituales de teatral presente, pasado y futuro, afirman y alaban los principios compartidos que habrán de guiar los pasos del nuevo gobierno, solicitan de su audiencia una contemplación de los valores tradicionales y confían en una "intensificación de efectos" por amplificación y reafirmación de lo que ya es conocido y creído. En este sentido, apuestan a moldear la memoria pública de forma duradera (Kohrs Campbell \& Hall Jamieson, 2008: 29-30).

Envuelto en una situación comunicativa ritual, el discurso de investidura se caracteriza estilísticamente, como señalan A. Álvarez e I. Chumaceiro (2009), por ser en alto grado formal, tanto en su registro lingüístico como en el protocolo social en el que se inscribe. Dicha formalidad se explica también en función del auditorio al que, de manera directa o indirecta, se dirige y del sitio, sancionado por la historia y la tradición, en el que por lo general se desarrolla, por el Congreso o la Asamblea Nacional. No sería exagerado

8 "Discurso inaugural", "discurso de asunción" o "discurso de investidura" son diferentes modos de nombrar el mismo acto institucional por el cual el presidente electo asume oficialmente como presidente a cargo del Poder Ejecutivo Nacional. Utilizaremos estos nombres de manera indistinta.

9 La traducción del inglés al español ha sido realizado por el autor.

10 Según Kohrs Campbell \& Hall Jamieson, "Presidential inaugurals are a subspecies of the kind of discourse that Aristotle called epideictic, a form of rhetoric that praises or blames on ceremonial occasions, invites the audience to evaluate the speaker's performance, recalls the past and speculates about the future while focusing on the present, employs a noble, dignified literary style, and amplifies or rehearses admitted facts" (2008: 29). 
afirmar que son verdaderos "acontecimientos mediáticos" (Dayan y Katz, 1992), transmitidos en directo por la radio y la televisión y reseñados en extenso por la prensa nacional. Los oradores, en circunstancias tan emblemáticas, procuran, por lo general, comunicar al auditorio su concepción ideológica y sus planteamientos políticos y de gobierno, con el objetivo de acumular capital retórico y prolongar el período de luna de miel de la nueva presidencia (Vitale, 2013, 2014).

Formal, constituyente, intemporal, elocuente, las características fundamentales del género pueden ceñirse -de acuerdo con Kohrs Campbell \& Hall Jamieson (2008: 30 - 31 $)^{11}$ - a cuatro actividades oratorias interrelacionadas: el discurso de investidura presidencial (1) unifica la audiencia por la reconstitución de sus miembros como "pueblo", quienes pueden presenciar y ratificar la ceremonia; (2) ensaya valores comunitarios extraídos del pasado; (3) describe los principios políticos que guiarán al nuevo gobierno; y (4) demuestran que el presidente es capaz de encarnar con propiedad su posición, dado que aprecia los requisitos y las limitaciones de la función ejecutiva. Cada uno de estas metas debería, asimismo, ser lograda a través de los medios apropiados al discurso epidíctico; esto es, articulando el pasado y el futuro, y elogiando la institución de la presidencia y los valores y formas de gobierno del que forma parte, todos procesos mediante los cuales el acuerdo entre el presidente y el pueblo es renovado.

En este sentido, y a modo de síntesis, el discurso inaugural, mediante la puesta en escena de una trama de valores, principios, requisitos y limitaciones, simultáneamente constituye la identidad del orador, postula la identidad del auditorio, oficia un mundo ético común (Maingueneau, 2002), del que se invita a participar a todos los destinatarios, incluso a los adversarios, y celebra la democracia misma como contrato social: "En el corazón del ritual descansa la intemporalidad epidíctica - la fusión del pasado y el futuro de la nación en un eterno presente- del pacto entre el ejecutivo y la nación, que es la esencia del gobierno democrático (Kohrs Campbell \& Hall Jamieson, 2008: 56).

\section{El discurso inaugural de "Cambiemos": los ciudadanos del siglo XXI}

\section{a. La refundación de "Cambiemos": los clivajes}

El DIM procuró desplegar un espacio discursivo que le permitiera al nuevo partido de gobierno legitimar una posición dominante en el campo político argentino. Este despliegue hizo pie en una retórica o estructura argumentativa fundacional, interesada en instalar una frontera entre el pasado reciente de la administración de Cristina Fernández de Kirchner (2007-2015) y el porvenir de "Cambiemos":

Señores Jefes de Estado; representantes de delegaciones extranjeras; invitados especiales; autoridades de la Corte; señores Gobernadores; miembros del Congreso reunidos en Asamblea; especialmente queridos argentinos: hoy se está cumpliendo un sueño, termina una época completa sin violencias y esto que parecía tan difícil se hizo realidad. Por eso, hoy más que nunca, les tengo que decir que tenemos que ser optimistas respecto de nuestra esperanza y de nuestro futuro ${ }^{12}$.

11 Las autoras realizan una síntesis del estado del arte respecto al género. La pertinencia de las características enumeradas para el género en Estados Unidos no parecen diferir significativamente de las que son habituales en otros países democráticos occidentales.

12 Con el fin de codificar gráficamente de una manera fácil y perceptible los extractos del DIM, se opta por citarlos con marginación y tamaño tipográficos diferentes. 


\section{Conexão Letras}

La introducción del DIM presenta en una oración concisa, no exenta de ambigüedades, las dos caras de una misma voluntad performativa: la del sueño improbable finalmente realizado ("hoy se está cumpliendo un sueño") y la del final no menos improbable de una época asimismo acontecido ("termina una época completa sin violencias"). Las dificultades superadas ("esto que parecía tan difícil se hizo realidad") redundan, mediante un argumento a fortiori, en "un mensaje de confianza" que no carece de los énfasis anímicos, ni deícticos, del optimismo, la esperanza y el futuro:

Quiero reiterarles un mensaje de confianza, decirles que este gobierno que iniciamos hoy va a trabajar incansablemente los próximos cuatro años para que todos los argentinos, especialmente aquellos que más nos necesitan, al terminar, estén viviendo mejor.

La reiteración del mensaje de confianza conduce del "optimismo" del conjunto social al trabajo incansable de la nueva administración. La promesa se inscribe entre esas dos facetas, y se sostiene sobre el argumento comparativo de la superación: después de cuatro años, se trata de vivir mejor. Esa será la vara con que la administración Macri pretende ser evaluada. Como sea, el sueño, el optimismo, la esperanza, la confianza, en suma: el horizonte de expectativas del DIM, se constituye a partir de un contraste con la situación precedente, que opera en el ámbito de lo que podríamos denominar "ánimo fundacional" (Aboy Carlés, 2001). Sea, ¿cómo se organiza entonces argumentativamente ese ánimo en el DIM, de modo tal que la celebración genérica de lo común no obture la calificación negativa del pasado inmediato?

La retórica fundacional del DIM, su retórica del "cambio", implica en los argumentos una promesa de gobierno construida punto a punto en las antípodas de la gestión anterior, tomando como base diferentes clivajes ${ }^{13}$, que dieron forma a la pars destruens y la pars construens de la alocución. Así, la constitución de una Argentina del siglo XXI -esto es, la frontera con el vicioso pasado denostado y la celebración de un horizonte de idealidad social- se organiza en torno a tres clivajes que dotan de coherencia y cohesión ese momento liminar: (1) el clivaje verdad / mentira; (2) el clivaje liderazgo / equipo; y (3) el clivaje unidad en la diversidad /enfrentamiento.

\section{El clivaje verdad/mentira}

Como eco de un cierto horizonte de sentido que corporaciones, agrupaciones y colectivos de variado alcance, espectro e ideología - desde las principales corporaciones mediáticas hasta partidos de izquierda y movimientos sociales variopintos- habían desplegado en torno al liderazgo de la presidente Cristina Fernández de Kirchner y a las características de las políticas de Estado por su gobierno alentadas, el clivaje verdad / mentira resulta uno de los mecanismos centrales de la retórica constitutiva del DIM.

13 La idea de clivaje social refiere a una división social que escinde a los ciudadanos entre quienes están a favor y quienes están en contra de una determinada cuestión. Si bien en su trabajo clásico, Party systems and Voter Alignments, Lipset y Rokkan "sostienen que un clivaje no es una división por cuestiones actitudinales, ideológicas o coyunturales, sino una fisura profunda que coloca a los individuos en uno u otro bando, más allá de su voluntad. No todas las divisiones de una sociedad conforman clivajes: para que se así suceda debe ser hondamente sentida (más que pensada) por los individuos" (citado en Vommaro, Morresi y Belloti, 2015: 436), en este artículo entendemos "clivaje" en un sentido más amplio, ciñéndonos a la idea rectora de la escisión dicotómica (a favor / en contra) de los ciudadanos. 
Con matices respecto de otros discursos de la etapa inicial del gobierno de “Cambiemos" $" 14$, más agresivos y polémicos, el clivaje se organiza en el DIM a partir de tres procedimientos retóricos menos orientados a la confrontación que a la erección, por contraste, de un nuevo tipo de liderazgo. El primer procedimiento, que marca el tono del exordio, es la construcción de un ethos presidencial próximo, sincero, empático y falible, con vocación de servicio, proclive a la comunicación "con todos los argentinos":

Hoy me han elegido para ser presidente de la Nación y me llena de alegría y de orgullo. Pero quiero decirles que voy a ser el mismo, aquel que esté cerca, que escuche, que les hable sencillo, con la verdad, que comparta sus emociones y que recuerde siempre que no es infalible. Y como presidente quiero ser un ciudadano que se pueda comunicar con todos los argentinos para transmitirles mis dudas, mis certezas, mis ideas, mi esperanza y todas mis ganas de hacer.

Esta imagen de hombre común, de sujeto afable, convencional, emocionalmente próximo y accesible, capaz de escuchar y de compartir sus pensamientos y sentimientos, ofrece una fisonomía de Macri alejada de ciertas representaciones previas en torno a su figura (la de empresario insensible, la de rico mandón, etc.), al mismo tiempo que la ubica en las antípodas de la imagen ególatra, autoritaria y engañosa con que se implica una y otra vez a la ex presidente Cristina Fernández:

Como les dije en la campaña para mí la política no es una competencia entre dirigentes para ver quién tiene el ego más grande, es el trabajo entre dirigentes modernos que trabajan en equipo para servir a los demás; la política tampoco es el escenario en que algunos líderes mienten para engañar a la gente y el mundo con datos falsos.

Bajo este formato de contrastes, la definición de la política cobra consistencia a partir de procedimientos de reformulación ("la política no es... es el trabajo...") y de negación ("la política tampoco es..."). Éstos aparecen aquí (y a menudo en la oratoria de Macri) como signo de una disputa latente, asordinada, y como síntoma de una voz en puja con su propia heterogeneidad constitutiva. Esta segunda característica del clivaje debería ser puesta en relación con una tercera: el carácter eminentemente propositivo del DIM, como corresponde a un género a la vez epidíctico y programático:

Quiero pedirles que nuestro lugar de encuentro sea la verdad y que podamos reconocer cuáles son nuestros problemas para que juntos encontremos las mejores soluciones.

El programa del DIM está regido por propuestas explícitas (v. i. sección B), cuyo horizonte incluye la pobreza, el narcotráfico y la unidad nacional; sin embargo, su fundamento aparentemente irrenunciable es "la verdad". Ésta constituye un significante nodal del DIM (y de toda la primera etapa de "Cambiemos"), casi una topografía ("lugar de encuentro"), que se vuelve condición de posibilidad de su fuerza persuasiva, reforzada por el uso de lexemas con carga de presuposición como "reconocer". Este vínculo debe ser destacado: no hay verdad en el DIM sin reconocimiento; esto es, la verdad implicaría una suerte de mayéutica, que pondría a "Cambiemos" en el lugar de la partera.

Por un lado, "la verdad", como el artículo definido indica, aparece como un lugar existente, neutro, a-semiótico, en el que sólo es posible el encuentro, porque no habría 


\section{Conexão Letras}

lógicamente espacio alguno para el conflicto. No hay en el sentido de la verdad lucha alguna, porque no habría, en esta concepción llana, falsamente desideologizada, polifonía posible. Por otro lado, esta condición a-semiótica de la verdad conduce a un ejercicio de "reconocimiento", una mayéutica política, en la que el acceso al conocimiento no está exento de dolor, porque implica despertar de un engaño, purgar la anestesia sensorial. La secuencia de entimemas conduce de la verdad como reconocimiento al reconocimiento como experiencia necesaria del dolor.

Verdad y dolor integrarían una relación complementaria, que organizaría la estructura elemental de la semiótica del DIM, en contraposición con la relación complementaria que habría de caracterizar al gobierno de los Kirchner (y por fuerza a todos los gobiernos "populistas"): mentira y felicidad. Mayéutica contra placebo. Ahora bien, comprender el sentido integral de esta estructura supone percibir que la verdad es momentáneamente dolorosa, porque la felicidad ha sido momentáneamente mentirosa. Es decir, estos pares se oponen apenasen el tiempo corto de la coyuntura, con vistas a un futuro mediato en el que la relación de complemento de esos pares se debilita hasta invertirse: verdad y felicidad irán de la mano una vez que el tránsito por el dolor, consecuencia de la mentira, se desvanezca ${ }^{15}$.

\section{El clivaje líder / equipo}

El cisma conceptual que implica el clivaje líder / equipo en el DIM rebasa los límites de lo que podríamos denominar "campo político"; esto es, excede con mucho la mera cuestión de las formas de ejercitar la política: las aparentemente más verticales y tradicionales del liderazgo alla siglo XX, sea uno populista o uno democrático, y las aparentemente más horizontales y a la moda del trabajo en equipo. Ocurre que lo que inicialmente puede ser visto como un simple modo de imaginar una forma de ejercicio de gobierno o, en un sentido más amplio, una forma de praxis política, se revela a una mirada más atenta como un frontera conceptual de índole cultural, que distingue entre una concepción clásica (o tradicional) y una concepción moderna de la organización social (recordar el calificativo: "dirigentes modernos"). Se trata, entonces, de entender este clivaje en su performación de una verdadera hermenéutica histórica:

En el siglo pasado la sociedad privilegiaba liderazgos individuales en todos los ámbitos: en la empresa, en la ciencia, en la academia, en la política, en todos los campos de la actividad humana se buscaban genios que lo resolvieran todo.

En el siglo XXI hemos entendido que las cosas salen bien cuando se arman equipos, se combinan los esfuerzos, el profesionalismo, la experiencia y las buenas intenciones de muchas personas.

El concepto de "liderazgo" o de "liderazgo individual" aparece en el DIM ligada a una cierta matriz romántica de la actividad humana, y en ese sentido interpreta adecuadamente una matriz de sentido que había estructurado la concepción kirchnerista de la política (cf. Dagatti, 2017b). Ahora bien, el énfasis en el pasaje de los liderazgos a los equipos parece menos una crítica (no se trata de una crítica de los liderazgos) que una concesión

15 El sentido de este juego de relaciones semióticas elementales puede comprenderse mejor si se lo concibe respecto de uno de los grandes problemas de la refundación de "Cambiemos": cuando no se cuenta con las ventajas de la evidencia (o con la fuerza de un verosímil que tienda a hegemonizar la concepción de la realidad), es perentorio ostentar una mayéutica del "reconocimiento", que habría de parir la verdad herrumbrada. 
evolutiva, una adaptación a los tiempos, como quien deja detrás el lastre de nociones gastadas, densas e desusadas. N. Fairclough, en su conocido artículo El lenguaje del nuevo capitalismo, daba cuenta de esta persuasión de lo irreversible como uno de los modos de aceptar la adaptación como el único camino viable.

La del DIM es más bien una visión técnica, oficiosa o profesional del ejercicio de la política, que se pretende plenamente conforme a las características del siglo XXI, que una visión romántica o artística del ejercicio de la política. La estructura isomórfica de la argumentación en el extracto citado, su paralelismo, refuerza el efecto de oposición, pero a su vez sugiere que ésta es menos una frontera conflictiva que una evolución "natural" (si entendemos por natural, esa segunda naturaleza que es la cultura, como afirmaba R. Barthes en Mitologías (2005)). (La semejanza de la estructura vuelve más evidente la oposición de los argumentos, al mismo tiempo que pule el conflicto en el plano de la forma). El uso del pretérito imperfecto ("privilegiaba", "se buscaban"), en un caso, y el uso en el otro del pretérito perfecto compuesto ("hemos entendido") marcan una frontera enunciativa, deíctica, que es tanto temporal (lo pasado, pisado, en un caso; lo pasado con consecuencias en el presente, en el otro) como personal (de la tercera persona a la primera del plural). Con otras palabras, la idea misma de liderazgo es vieja, arcaica, conservadora, por oposición a la idea moderna de equipo, que permearía todos los ámbitos de la vida social.

Las tensiones entre las lógicas de funcionamiento de una democracia hiper-presidencialista como la argentina y la visión del trabajo en equipo que propone el DIM colocan al presidente orador ante una paradoja, que la idea de "armar buenos equipos" vendría a resolver sin necesidad de disputas:

A lo largo de mi vida, en el ámbito del deporte, en los 8 años que tuve el honor de conducir el Gobierno de la Ciudad de Buenos Aires, pude armar buenos equipos que construyeron soluciones concretas para los problemas de la gente. En este nuevo desafío, para hacer los cambios a los que nos comprometimos, necesitamos armar equipos diversos, sumar visiones distintas de nuestra realidad.

El carácter biográfico, experiencial, de la primera oración se inscribe en la segunda en una deontología del equipo que garantizaría el compromiso electoral asumido, traducido invariablemente a la retórica motivacional del "desafío", que, en la línea de nuestro argumento anterior, supone una actitud reactiva, adaptativa, a las prescripciones ineluctables de la actualidad. El paradigma problema-solución ${ }^{16}$, recurrente en los discursos de "Cambiemos", ofrece a este trabajo en equipo un molde concreto de acción.

Ideología, liderazgos enfáticos y conflicto integran una trilogía de la política "antigua" que se opone punto por punto a una concepción práctica (servicial), colectiva y consensual de la política moderna. Así, en un folleto titulado "Preguntas y respuestas", distribuido entre cuadros del partido PRO en 2011, se lee:

Seguir catalogando las propuestas políticas como pertenecientes a la derecha o a la izquierda es aplicar al presente categorías del pasado, que en vez de explicar confunden. Hay distintos modos de ver la política: algunos son antiguos y otros son modernos. Según la perspectiva moderna la política es gestión y servicio al ciudadano. El PRO sostiene esta última concepción, y busca favorecer el desarrollo nacional a través de la búsqueda de consensos y de unidad. Al votante no le preocupan las clasificaciones entre derecha e izquierda,

16 Véase al respecto un análisis más general sobre el paradigma problema-solución en ¿Desea usted ser evaluado? de J.-A. Miller y J.-C. Milner (2004). 
quiere gobernantes honestos que trabajen seriamente en la solución de los problemas y en la generación de condiciones para el crecimiento de todos ("Preguntas y respuestas", en Morresi, 2015: 179-180).

A distancia de la imagen demodé de los líderes románticos, que es decir por eso mismo ideológicos, un ethos de dirigente armonizador, que conjuga la biografía pública del político, el estilo próximo del orador y una exitosa imagen previa como dirigente deportivo, parece resultar el mecanismo dóxico, la doxa, capaz de resolver la paradoxa. En Hagamos equipo, G. Vommaro y S. Morresi (2015: 54) destacan este carácter ensambleísco (ya que no asambleísco) del presidente Macri: "El líder, más que definir ideas, dirigir o cumplir el rol de tomador de decisiones, funciona como un 'armonizador', alguien capaz de escuchar todos los puntos de vista, combinar algunos de ellos e implementarlos de un modo tal que parezca que todos han colaborado en la definición del camino".

\section{El clivaje unión en la diversidad / enfrentamiento}

La “diversidad" aparece en el DIM tramada por zonas del saber y del deber: es constatada, afirmada y vinculante. Existe, siempre ha existido, caracteriza nuestra identidad como país (después de todos, un ideologema, el de "crisol de razas", atraviesa nuestros mitos fundacionales), a la vez que nos conmina, por su sola presencia, a la unión, a la convergencia de intereses y objetivos. Así, del reconocimiento de la diversidad nacional se deduce un deber de integración o de unión:

Argentina es un país con enormes diversidades. En cada provincia, en cada lugar se han desarrollado distintas formas de ver la realidad. Estas deben integrarse en un país unido en la diversidad. Queremos el aporte de todos, de la gente que se siente de derecha y de la gente que se siente de izquierda, de los peronistas y de los antiperonistas, de los jóvenes que están en la edad de la trasgresión y de los mayores que aportan su experiencia, porque precisamente esa diversidad es la que nos enriquece y nos hace mejores.

Apenas presentado el tópico de la diversidad de manera didáctica y prescriptiva ("Argentina es... Estas deben..."), una estructura isomórfica, esta vez de carácter antitético, organiza la argumentación del DIM y explicita el contraste entre sectores diferentes (o incluso históricamente enfrentados: peronistas y antiperonistas, derecha e izquierda), a la vez que sugiere menos una frontera, la del enfrentamiento, que la del necesario reconocimiento en pos de la diversidad: "Queremos el aporte de todos, de la gente que se siente de derecha y de la gente que...". El "todos" es anterior a las divisiones, enumeradas en una cuidada balanza de cláusulas, que apuesta al equilibrio integral de las diferencias antes que a la antítesis de los extremos (cf. Barthes, 2005). El contraste de las partes, actores o sectores sucumbe al equilibrio de la forma, mientras que la enumeración antitética ofrece un modo estereotipado, y por lo tanto familiar (cf. Amossy, 2000, "figuras muertas"), de volver cándidamente emotiva la enumeración.

La mutua convergencia de constatación y deseo, de saber y querer ("Argentina es... Queremos el aporte de todos..."), vuelve al "enfrentamiento" y a la "prepotencia" animales raros de la coyuntura nacional. La incredulidad ostensible del orador ("Todo esto reconozco que puede...") constituye retrospectivamente a la unión en la diversidad ${ }^{17}$ como una de las demandas centrales de los argentinos de cara a la reciente elección:

17 Aunque no es este artículo el lugar para realizar una crítica a la celebración indiscriminada de la diversidad y la pluralidad, no quisiéramos dejar de señalar cómo el discurso de la diversidad se articula de buena manera con la completa indiferencia por las consecuencias de la desigualdad. Véase al respecto el provocador e inteligente texto de T. Eagleton Cultura (2017). 
Todo esto reconozco que puede sonar increíble después de tantos años de enfrentamientos inútiles, pero es un desafío excitante, es lo que pidieron millones de argentinos que estaban cansados de la prepotencia y del enfrentamiento inútil.

El carácter de la unión en la diversidad como demanda resulta subrayado por el presupuesto que late en la noción de "reconocimiento" que el orador propone como operación subjetiva ("reconozco que"). La "prepotencia" y el "enfrentamiento inútil" aparecen como la contracara de la demanda de los argentinos, pero además colocan en escena una representación del abuso de poder y del abuso de ideología del gobierno precedente. El calificativo "inútil" sugiere, en otro sentido, que el problema no es tanto el enfrentamiento, sino el enfrentamiento por el enfrentamiento mismo, dejando inferir que la reivindicación del conflicto desplegada por el kirchnerismo era la máscara ideológica del rostro de la mentira. El "cansancio", asimismo, aparece como una figura recurrente que coloca los abusos en una clave energética ${ }^{18}$.

La disociación de nociones "diversidad / división" le permite al DIM reivindicar la primera mientras censura la segunda. Sumemos a este respecto la concepción de la "derecha" y de la "izquierda" menos como aspectos esenciales (o vitales) que sentimentales de los ciudadanos (v. s. "de la gente que se siente de derecha y de la gente que se siente de izquierda") y tendremos una celebración de la unión en diversidad de la cual el DIM se asume como momento fundante o instituyente:

El país tiene sectores que piensan de diferentes maneras, pero no está dividido, los ciudadanos votaron como quisieron: unos apoyaron nuestra visión y otros respaldaron a otros candidatos. Eso nos alegra porque pudieron elegir en libertad, pero ya pasaron las elecciones, llegó el momento en el que todos debemos unirnos para crecer y mejorar para que nuestro país avance.

Cuando Macri indica en el DIM que "ya pasaron las elecciones, llegó el momento en el que todos debemos unirnos..." está marcando uno de los momentos centrales del género "discurso inaugural": el de la constitución del pueblo como unidad, que viene a suturar la ficción divisoria de las elecciones, acentuada en el caso que nos ocupa por la instancia de balotaje. No por casualidad este acto performativo del pueblo unido separa en el DIM el tramo de los clivajes del tramo eminentemente programático, en el que el orador establece (y por lo tanto funda) los motivos de su victoria electoral. Estos tres ejes, que se repetirán a lo largo de los primeros meses de gobierno, de manera especial en los actos institucionales (discursos ante la Asamblea Legislativa, efemérides), son conocidos: "pobreza cero", "derrotar el narcotráfico" y "unir a los argentinos" (v. i. sección B).

Considerando los dos grandes tramos del discurso, el de los clivajes y el del programa, no parece aventurado afirmar que la "unión" opera como el fondo de operaciones del DIM y, por lo tanto, como apuesta vertebradora de la constitución de una nueva Argentina. Pars destruens y pars construens del texto giran en torno a esta noción, enunciada por el DIM como "clave de la construcción de la Argentina del Siglo XXI":

La forma de lograr estos grandes objetivos [pobreza cero y vencer el narcotráfico] es simple, el diálogo, el respeto, la suma de visiones, son objetivos comunes y su realización requiere como paso fundamental que nos unamos para alcanzarlos. Ese objetivo, el de unir a los argentinos, el de poner nuestros puntos en común sobre nuestras diferencias, integrán-

18 Si bien no es el objeto de este artículo, no podemos dejar de indicar que toda una retórica de la energía atraviesa el DIM. 
dolas y respetándolas, es la clave de la construcción de la Argentina del Siglo XXI a la que nos encaminamos hoy.

El diseño de "la Argentina del Siglo XXI", de la Argentina moderna, de la Argentina de "Cambiemos", tiene por condición principal, entonces, la de la unión de los argentinos. El "tiempo nuevo" que el DIM propone, cuyo tono fundacional resulta notorio, es "el tiempo del diálogo, del respeto y del trabajo en equipo":

Se viene un tiempo nuevo, el tiempo del diálogo, del respeto y del trabajo en equipo, tiempo de construcción con más justicia social. Repetidamente a lo largo de la historia hemos vivido muchas divisiones, la confrontación nos ha llevado por caminos errados, somos pasionales y es bueno serlo, pero a veces esa pasión nos tiende una trampa, crea conflictos innecesarios, genera fanatismos que tantas veces nos arrastraron a la violencia, a la incapacidad de razonar y a la falta de amor.

La disimilitud entre la forma impersonal del tiempo por venir ("Se viene...) y la forma personal de la historia ("Repetidamente a lo largo de la historia hemos...") parece sugerir al mismo tiempo la inevitabilidad del futuro y la inscripción del orador como uno más en el colectivo de los argentinos. La frontera nítida entre el pasado y el futuro, entre la historia y el tiempo nuevo, contrasta con la frontera difusa entre las formas de la violencia, del fanatismo y de la irracionalidad adjudicadas al pasado, donde el genocidio dictatorial parece acercarse demasiado a las variantes del populismo democrático. Así, la descripción de los "conflictos innecesarios" subsume de una manera neblinosa terrorismo de Estado, lucha armada, conflicto político, violencias, falta de amor, en una suerte de vaguedad conceptual basada en las trampas de la emoción, que, como en el refrán del agua sucia y el bebé, arrastra desde una visión new age todo atisbo de conflicto político.

La retórica constitutiva del DIM implica en este sentido una nueva hermenéutica histórica para la cual el vicio del pasado argentino se condensa en el enfrentamiento, en la violencia, en la confrontación, en el conflicto inútil, en suma: en distintas variantes de autoritarismo, colocando en una misma serie, de una manera apenas implícita, las dictaduras militares y los gobiernos autodenominados "nacionales y populares". Sin ir más lejos, la noción de "enfrentamiento" conduce en el DIM a una definición del término "autoritarismo", entendido de una forma amplia como lo contrario de libertad, de acuerdo, de felicidad, e incluso de "ley":

Tenemos que sacar al enfrentamiento del centro de la escena y poner en ese lugar al encuentro, el desarrollo y el crecimiento. En la pelea irracional no gana nadie, en el acuerdo ganamos todos. Para trabajar juntos no hace falta que dejemos de lado nuestras ideas y formas de ver el mundo, tenemos que ponerlas al servicio de nuestro proyecto común y lograr la construcción de un país en el que todos podamos conseguir nuestras formas de felicidad. Podemos pensar de distinta forma, pero la ley debe ser respetada, una cosa es tener distintas visiones, ideas y propuestas, otra avasallar las instituciones con proyectos personalistas o hacer uso del poder en beneficio propio, ahí no hay una cuestión de opiniones diversas, se trata de la transgresión de la ley. El autoritarismo no es una idea distinta, es el intento de limitar la libertad de las ideas y de las personas. Este gobierno va a saber defender esa libertad que es esencial para la democracia.

La asociación por contigüidad entre "enfrentamiento" y "autoritarismo" constituye una operación central del momento inaugural de "Cambiemos", paralela a la de asociar 
"libertad", “acuerdo", “diversidad” y "felicidad”. El DIM despliega, bajo esta estructura elemental, dos conjuntos semánticos nítidamente separados, aun cuando los términos que los integran disten de estar tan nítidamente asociados: de un lado, enfrentamiento, pelea irracional, avasallamiento de las instituciones con proyectos personalistas, uso del poder en beneficio propio, transgresión de la ley; en una palabra: autoritarismo; del otro lado, encuentro, desarrollo, crecimiento, diversidad, felicidad, libertad; en una palabra, democracia. Deontología y didáctica componen esta zona de la alocución: en parte, la mención de deberes u obligaciones ("tenemos que", "no hace falta", "la ley debe ser respetada"); en parte, cuasi eslóganes ("En la pelea irracional no gana nadie, en el acuerdo ganamos todos") y definiciones por disociación ("una cosa es..."), designación ("se trata de...", "esa libertad que es esencial para la democracia”) y reformulación ("El autoritarismo no es..., es el intento de...").

La antinomia democracia / autoritarismo deja fuera de campo el problema de las identidades colectivas o de las formas de comunidad. Como un síntoma de lo reprimido, esta antinomia del DIM es seguida por un párrafo sobre "el nacionalismo", cuya connotación patológica asoma apenas presentado el tema:

Aspiramos a un nacionalismo más sano que no se logra partiendo del rencor, la enemistad, la lucha permanente o la demonización del otro, el verdadero amor por el país es antes que nada amor y respeto por su gente, por toda su gente. La Patria es más que sus símbolos, somos las personas que vivimos en ellas a las que hay que cuidar, ayudar y desarrollar.

La didáctica de la libertad recibe el suplemento de una didáctica del nacionalismo, que opera por medio de una serie de operaciones de sinonimia, reformulación, disociación y definición. El DIM sustituye "nacionalismo" por "amor por el país"; esta sustitución participa de un proceso más amplio de reformulación por negación metalingüística (“Aspiramos a un nacionalismo más sano que no se logra... el verdadero amor por el país es...”), que establece una disociación nocional entre el nacionalismo entendido como rencor, enemistad, lucha permanente, demonización del otro o mera simbología y el nacionalismo definido como "amor y respeto" por la gente del país. Estas operaciones de forjado de una noción sana de nacionalismo (una disociación, por cierto, en el terreno nada neutro de una semántica médica) adquieren toda su dimensión al integrarse a una distinción entre un nacionalismo declamado (simbólico, nominal, ideológico), que sería aquel de las formas autodenominadas "nacionales y populares" de gobierno, y un nacionalismo aplicado, seco, orientado al cuidado, la ayuda y el desarrollo de las ciudadanos.

\section{b. El programa de "Cambiemos":}

La "unión de los argentinos" es el principal, pero, como dijimos, no el único de los ejes de la pars construens del DIM. "Pobreza cero" y "derrotar el narcotráfico" constituyen, junto al propósito de la unión, el tramo eminentemente programático del DIM:

La mayoría de los argentinos que votó por nuestra propuesta lo hizo basada en tres ideas centrales. Ellas son: pobreza cero, derrotar el narcotráfico y unir a los argentinos

No resulta extraño, por esa razón, que predomine una inscripción enunciativa en términos de gobierno o propuesta, el "nosotros gubernamental", que, no obstante, coexiste con el colectivo de los argentinos: 
Hablar de pobreza cero es hablar de un horizonte, de la meta que da sentido a nuestras acciones. Nuestra prioridad será lograr un país donde cada día haya más igualdad de oportunidades, en el que no haya argentinos que pasen hambre, en el que todos tengamos la libertad de elegir dónde vivir y desarrollar nuestros sueños.

Quiero darles una vez más la confirmación de que vamos a cuidar a todos. El Estado va a estar donde sea necesario para cada argentino, en especial para los que menos tienen. Vamos a universalizar la protección social para que ningún chico quede desprotegido. Vamos a trabajar para que todos puedan tener un techo con agua corriente y cloacas y vamos a urbanizar las villas para transformar para siempre la vida de miles de familias.

Cuando se presta suficiente atención al DIM, es posible percibir el desdoblamiento de la tarea del Estado en términos activos y en términos reactivos: un perfil bifronte. De un lado, una dimensión reactiva, atravesada por una semántica del cuidado y la protección que, pese a su horizonte totalizante ("vamos a cuidar a todos"), se ocuparía de focalizar su atención en los sectores más vulnerables de la trama social; allí donde sea necesario: "El Estado va a estar donde sea necesario... en especial para los que menos tienen", "no haya argentinos que pasen hambre", "ningún chico quede desprotegido", "todos puedan tener un techo con agua corriente y cloacas", "urbanizar las villas para transformar para siempre la vida de miles de familias". Del otro lado, una dimensión activa, orientada menos al cuidado y la protección del conjunto y de las partes que a una operación de ampliación de la economía (por la ocupación de fuerza de trabajo disponible, por el aprovechamiento de "los enormes recursos naturales y humanos que tiene la Argentina"), de cuya suerte depende una especie de derrame ${ }^{19}$ hacia el conjunto $\mathrm{y}$, de manera especial, a los sectores desfavorecidos:

Pero para que haya en realidad pobreza cero necesitamos generar trabajo, ampliar la economía, aprovechar los enormes recursos naturales y humanos que tiene la Argentina, vamos a cuidar los trabajos que hoy existen, pero sobre todo a producir una transformación para que se multipliquen las fuentes de trabajo, porque esa es la única forma de que haya prosperidad donde hoy hay una pobreza inaceptable. El desarrollo de la Argentina llegará a través de una inversión inteligente y expansiva, que mejore la infraestructura, ponga las bases para el crecimiento de la producción, traiga oportunidades y genere la prosperidad que merecemos.

El contraste del párrafo anterior con el que le precede está indicado, en primer lugar, por el marcador adversativo que encabeza el párrafo ("Pero") y, en segundo lugar, por el operador de refuerzo argumentativo "en realidad", que tiene por significado vigorizar como argumento el miembro del discurso en el que se encuentra ("para que haya en realidad pobreza cero necesitamos...”), al tiempo que indica que éste tiene más peso argumentativo que otros miembros anteriores anti-orientados (en síntesis: la confirmación del cuidado por parte del Estado). La combinación sintagmática de estos dos elementos marcador adversativo y operador de refuerzo- brinda argumentos para entender el pasaje del momento reactivo al momento activo. La frase "vamos a cuidar los trabajos que hoy

19 Por razones de hegemonía discursiva, la palabra "derrame" constituye un tabú (o cuanto menos, un término marginal) del campo de la economía política nacional, ya que está asociada ideológicamente con las políticas neoliberales. La ausencia de esa noción no debe hacernos perder de vista, sin embargo, la lógica de "derrame" que da consistencia a los argumentos del DIM: "el desarrollo de la Argentina" depende de "una inversión inteligente y expansiva", "ampliar la economía" es condición sine qua non de la "transformación", es "la única forma de que haya prosperidad donde hoy hay una pobreza inaceptable". 
existen, pero sobre todo a producir una transformación..." iría en este mismo sentido. La explicación de este perfil desdoblado puede adjudicarse a una negociación del DIM con el concierto de voces ajenas (condensados, por ejemplo, en la denominada "campaña del miedo" del candidato rival Daniel Scioli) que afirmaban sin remilgos el triunfo de una fuerza autoritaria, interesada en favorecer a las elites y despreocupada por el bienestar del conjunto de la población. El DIM se orienta a satisfacer de manera simultánea las demandas de transformación económica de las relaciones Estado-mercado, realizadas por ciertos sectores de las elites locales y foráneas, y las demandas de un Estado presente, realizadas por un amplio y heterogéneo conjunto de las fuerzas sociales.

"Derrotar el narcotráfico" es, como dijimos antes, el tercero de los ejes de la parte programática del DIM. Como a menudo en la oratoria de Macri, el componente programático se presenta bajo la forma de un "desafío":

Otro de los grandes desafíos que va a tener nuestro gobierno es el de combatir el narcotráfico como ningún otro gobierno lo hizo antes. Miles de personas a lo largo de todo el país me transmitieron su profunda preocupación por este tema, hay jóvenes que matan y mueren sin saber por qué, actuando bajo los efectos del paco y de la droga. La droga arruina la vida de familias enteras, no podemos resignarnos ni aceptar esta realidad como algo natural. Vamos a encarar ente tema de frente y vamos a trabajar con inteligencia y decisión para devolver tranquilidad y seguridad a las familias en todo el país. Aunque el narcotráfico ha crecido en los últimos años de manera alarmante estamos a tiempo de impedir que se consolide, el tema es difícil y complejo, pero vamos a crear los mecanismos necesarios que nos permitan llegar a la solución que queremos.

Si dejamos de lado la euforia de la promesa, el DIM presenta la lucha contra el narcotráfico como el resultado de la escucha de los ciudadanos. Es un ejemplo notorio de construcción retrospectiva de la demanda. También es una ostentación de la proximidad que "Cambiemos" había convertido en eje de su campaña electoral. En este sentido, una hipótesis sobre el discurso de Cambiemos es la de poner en escena una proximidad de la demanda y una abstracción de la oferta. De hecho, los extractos antes citados sugieren cierta tendencia del DIM a la nominalización y a la abstracción, que parecen ir en sintonía con "el lenguaje del nuevo capitalismo" descrito por Fairclough (2000): "pobreza", "ampliar la economía", "producir una transformación”, "felicidad”, "tranquilidad”, "seguridad", "desarrollo", "inversión inteligente y expansiva", "crecimiento", "prosperidad" (o "creatividad", "innovación”, "integración”, “colaboración”, como veremos más abajo). No se trata, claro está, de un caso único en el campo político, pero no deja de llamar la atención la generalidad e indeterminación de los argumentos del DIM: la solución al problema del narcotráfico, sin ir más lejos, está formulada sin ninguna referencia concreta: "trabajar con inteligencia y decisión", "devolver tranquilidad y seguridad", "el tema es difícil y complejo", "vamos a crear los mecanismos que...".

Los tres ejes principales - pobreza cero, derrotar el narcotráfico y unión de los argentinos- no agotan el programa del DIM. También se mencionan otros objetivos básicos como la lucha contra la corrupción, la defensa de una justicia independiente o "una revolución en la educación". Este objetivo final presenta un carácter fundacional indeleble:

Otro pilar importante de nuestro gobierno será liderar una revolución en la educación. No se trata de recuperar la educación argentina, se trata de crear una educación amplia, inclusiva, atenta a su calidad y acorde a las realidades del Siglo XXI. Este nuevo siglo ha traído nuevas posibilidades y nuevos desafíos al mundo entero, no podemos seguir pensando en la 
educación con las ideas y los objetivos del pasado. Tampoco podemos creer que el trabajo, la salud, la seguridad, el diálogo o nuestra forma de votar pueden seguir pensándose y gestionándose con ideas viejas.

Con prescindencia de los énfasis, el carácter revolucionario del objetivo educativo se justifica, notoriamente, por la adaptación del área "a las realidades del Siglo XXI". En este sentido, el propósito está supeditado a la prescripción de la época: "no podemos seguir pensando...". No deberíamos subestimar la fuerza que este deber tiene en la construcción del perfil político y cultural de "Cambiemos". Tal como sugiere la oración final del extracto precedente, la educación es un ítem más (no el menor, pero tampoco el único) en una serie de áreas o temáticas a revisar debido al envejecimiento ideológico de los abordajes. En efecto, todos los clivajes que mencionamos antes precisan ser considerados a la luz del parte-aguas central del DIM, el de la frontera entre el siglo XX y el siglo XXI:

Hay que mejorar todo lo que haya que mejorar, hay que animarse a responder con recursos nuevos a nuestros problemas, hace falta osadía de ideas, osadía de invención y atrevimiento de proyectos nuevos y distintos. La entrada al Siglo XXI, que la Argentina en cierto sentido ha retrasado, es una gran responsabilidad de este gobierno y es un motivo de gran excitación, de gran entusiasmo. Invitamos a todos a sumarse a esta apasionante tarea de ser pioneros de un mundo nuevo.

La retórica constitutiva del DIM descansa notablemente sobre "la entrada al Siglo XXI", que se habría visto retrasada por el gobierno de una fuerza que, más allá o más acá de sus virtudes y vicios, era, sobre todo, vieja: vieja por su concepción de la política, vieja por su exceso de ideología y su falta de soluciones, vieja por su propia fecha de nacimiento, ya que, conviene no olvidarlo, "Cambiemos" se presenta a sí mismo como el único partido político nascido en el siglo XXI. En efecto, el carácter constituyente del DIM juega sobre la línea que separa lo viejo, lo antiguo, lo perimido, de lo nuevo, lo moderno, lo por venir; es una separación secular, que cuenta a su favor con la condición irreversible del tiempo: el siglo XXI enfrentado al siglo XX. Los liderazgos mesiánicos o románticos, los excesos de ideología, que conducen inevitablemente al enfrentamiento inútil, a la pelea irracional, a la mentira, o sea al autoritarismo, deberían de ser entrevistos en su real dimensión en esta clave secular. La idea de "ser pioneros de un mundo nuevo", expresada, como veremos, en la peroratio del DIM, lleva este argumento al extremo.

Un documento partidario redactado por algunos de los principales dirigentes del PRO, años antes de conformar la alianza Cambiemos, intitulado Nuestra idea, expresa estos argumentos de una manera inmejorable:

Nuestro desarrollo y nuestro trabajo pertenecen al siglo XXI. Elegimos hacer política en el siglo XXI. Todas las otras opciones políticas pertenecen al siglo XX. Su universo de ideas es de otra época. Eligen vivir y hacer política en el siglo XX. Nuestras diferencias no son ideológicas, son cronológicas (p. 1) (en Vommaro, 2015: 138).

"Diferencias cronológicas": no se podría encontrar una manera mejor de expresar un corte fundacional con el pasado inmediato y con el pasado largo del siglo XX. Es una diferencia generacional expresada conceptualmente de una forma que va más allá de la mera cuestión etaria: el siglo XXI de "Cambiemos" es un siglo que empieza tarde, que llega a la Argentina cuando la gestión kirchnerista entrevé su ocaso. Esta apuesta por 
la constitución de un país del "siglo XXI" le ha permitido a la nueva administración, entre otras cosas, presentarse como una fuerza pos-ideológica, para la que la topología derecha-izquierda no significa nada (o sólo un pasado lejano), reivindicar la fuerza de los equipos en contra de los liderazgos, reivindicar la diversidad, sobre todo ligada a valores pos-materiales (ecología, velocidad del tránsito, etc.), en contra del autoritarismo. Estas características redundan en la construcción de una identidad política "moderna", que, como señala con criterio Morresi (2015), no es necesariamente antipolítica.

\title{
c. La peroratio del DIM: síntesis y garantía
}

La peroratio del DIM ofrece, de manera lógica, un cierre a los principales argumentos desplegados durante la alocución. Se pueden mencionar al respecto dos operaciones retóricas fundamentales: la recapitulación de los momentos fuertes del discurso y la construcción de la imagen del orador como garante de la nueva época.

El inicio del tramo final es básicamente una síntesis de los principales objetivos de la administración, tamizados por una enunciación de fuerte impronta subjetiva:

\begin{abstract}
Desde hoy, con Gabriela y todo nuestro equipo, vamos a hacer el mayor de los esfuerzos para que los habitantes de esta tierra rica y hermosa puedan vivir cada día mejor, porque eso es la política para nosotros. Quiero ser el Presidente que pueda acompañarlos en su crecimiento, el Presidente del desarrollo del potencial de cada argentino, del trabajo en equipo, de la igualdad de oportunidades; el Presidente de la creatividad y la innovación, el Presidente de la integración y la colaboración entre distintos sectores, el Presidente del trabajo, de las soluciones de una Argentina unida y de pie.
\end{abstract}

El extracto comienza con una definición de la política: "vamos a hacer el mayor de los esfuerzos para que los habitantes de esta tierra rica y hermosa puedan vivir cada día mejor, porque eso es la política para nosotros", que es una definición de la abundancia y no de la escasez y que incluye un elogio del país. Este elogio no será el único recurso patémico en juego. Más allá de la mención de "Gabriela" como estrategia nominal de proximidad, la abundancia de adjetivos calificativos y de marcadores de énfasis opera en esa dirección. Enseguida, el orador define, a través del uso emotivo de la anáfora, cómo quiere ser visto: "Quiero ser el Presidente que... el Presidente del...". La sucesión de formas nominales, y su grado de desubjetivación y abstracción, ofrecen nuevamente un panorama cuanto menos indeterminado de las "soluciones concretas" (v. s. sección B).

Este tramo inicial es seguido por una suerte de síntesis de los argumentos antes desarrollados, que expresa el "mensaje central" del DIM: en primer lugar, y de manera expresa, la convocatoria global del gobierno a implementaren la sociedad argentina "el arte del acuerdo", dejando de lado "el tiempo de la confrontación", que es el tiempo de las ideologías, de los prejuicios y, por eso mismo, de la confusión; en segundo lugar, y de manera mostrada o connotada, tal como sugiere el carácter temporal del sintagma precedente, el despliegue del ethos moderno de "Cambiemos" como "una nueva visión de la política", como "hijos de este tiempo", es decir, del siglo XXI:

Quiero terminar una vez más diciéndoles el mensaje central que quiero transmitirles hoy: convoco a todos a aprender el arte del acuerdo. Desafiemos todo lo que alguna vez nos haya confundido, está en nuestras manos y en la de todos nosotros superar las situaciones que nos hayan separado y desviado del camino del crecimiento. 
Tenemos una visión nueva de la política. Somos hijos de este tiempo y tratamos de comprenderlo sin prejuicios ni rencores. Es necesario superar el tiempo de la confrontación.

Superar, dejar atrás, ser hijos de este tiempo, asumir desafíos, vivir la aventura, entrar al siglo XXI, ser pioneros de un mundo nuevo: el progreso y el desarrollo como ideología colectiva e individual se vuelve la referencia insoslayable del espíritu "moderno" del DIM, como sugiere también la mención de Arturo Frondizi:

Arturo Frondizi dijo una vez: "por su magnitud el desafío que nos aguarda no es cosa de una persona ni de un grupo de personas, es tarea de todo el pueblo argentino e implica también una responsabilidad compartida por todos".

Lo cito porque creo profundamente en esas palabras, el país lo vamos a sacar adelante entre todos, no dudo de nosotros, el deseo de progreso fue la base de nuestra nación. Todo lo que somos fue hecho por personas que apostaron con un optimismo inteligente por el resultado de su trabajo. Lo que da sentido a nuestras vidas es esa aventura de crecimiento, vivámosla juntos, es una aventura extraordinaria.

La referencia al ex presidente argentino (1958-1962, derrocado por una dictadura militar) deja inferir la búsqueda de una filiación del DIM con ciertas líneas progresistas-desarrollistas de los relatos nacionales, que le permiten diseñar una imagen del futuro deseable con una paleta en la que a la experiencia trunca desarrollista se le agrega, en el extracto siguiente, la aventura mítica de los pioneros.

Finalmente, el sentido de toda la pieza oratoria descansa en el papel del propio orador como garante del "nuevo tiempo", del mundo ético de la "nueva Argentina": el de la unión, el del desarrollo, el de la verdad. Esa es la razón por la cual la sinceridad, la franqueza y la falibilidad convergen en los párrafos finales del DIM:

Quiero decirles por último que siempre voy a ser sincero con ustedes, creo que es la base de la confianza que me tienen y que pretendo preservar e incrementar. Y parte de esa sinceridad decirles que los desafíos que tenemos por delante son enormes y que los problemas no los vamos a poder resolver de un día para el otro, pero las grandes transformaciones se hacen dando pequeños pasos todos los días, y eso les aseguro nos llevará a estar cada día un poco mejor.

Cuento con ustedes para gobernar, necesito de su aporte, necesito que nos marquen nuestros errores, porque sabemos que no somos infalibles y tenemos un enorme compromiso con hacer, con hacer mucho. Hemos aprendido que cuanto uno más hace, más se equivoca. Por eso es ahí donde los necesito, porque esto lo hacemos juntos. Y quiero decirles desde el fondo de mi corazón que estoy convencido que si los argentinos nos animamos a unirnos seremos imparables.

Vamos juntos argentinos, vamos Argentina, vamos Argentina, muchas gracias.

La verdad, la diversidad, el trabajo en equipo, la unión, que constituyen los ejes rectores del nuevo tiempo anunciado por el DIM, encuentran en la imagen sincera, franca y falible del orador una garantía del mundo ético que a lo largo de su alocución el orador postuló como espacio de identificación y universo de pertenencia. Como afirman I. Chumaceiro y M. J. Gallucci (2007), los presidentes aprovechan la instancia de investidura 
no sólo para inaugurar una nueva administración, anunciar un programa y una filosofía de gobierno, sino también para construir su propia identidad y la de su audiencia. Digamos más: para construir todo un mundo ético común.

Esta convergencia de sinceridad, franqueza y falibilidad cierra la presentación de sí con que Macri había iniciado su discurso, apenas después de las salutaciones y del anuncio de una nueva etapa, cuando había prometido, como indicamos en el apartado II.A, "ser el mismo, aquel que esté cerca, que escuche, que les hable sencillo, con la verdad, que comparta sus emociones y que recuerde siempre que no es infalible".

La garantía del orador opera, como nos recuerda D. Maingueneau (2002), como fuente de legitimación del mundo ético desplegado. El lazo entre garantía y confianza es fundamental, sobre todo a la luz de la "campaña del miedo" que había rodeado su victoria electoral, cuando se asociaban a su futura gestión el retorno a los peores momentos del modelo neoliberal. El DIM responde a las voces del miedo con una apuesta por la confianza como núcleo fundamental de su ideario comunitario. Sabemos desde Aristóteles (2005: II, 5) que la confianza "es evidentemente lo contrario al miedo: [...] de manera que la confianza es una expectación acompañada de la imaginación de que están cerca las cosas salvadoras y de que las cosas temibles o no existen o están lejos".

\section{Consideraciones finales}

La crisis neoliberal de principios de siglo dejó en la Argentina el saldo de una mutación del campo político nacional. No parece casualidad que las dos fuerzas que han gobernado el país después se hayan configurado como tales entre las esquirlas del período anterior. La rivalidad entre el kirchnerismo y PRO, a la postre principal fuerza de la coalición "Cambiemos", cobró progresivamente forma a medida que el primero viró hacia una lógica populista de construcción de identidad política y el segundo comenzó un ascenso paulatino en las consideraciones de la sociedad y de los principales medios de comunicación, primero como gobierno de la Ciudad Autónoma de Buenos Aires, Capital Federal de la Argentina, y luego como contrincante de alcance nacional en las elecciones de 2011, 2013 y 2015. La victoria de Cambiemos en los comicios presidenciales de 2015 no careció de sorpresa, pero tampoco hizo saltar la banca.

El propósito de este artículo fue dar a conocer los resultados de un trabajo empírico en curso acerca de la construcción de hegemonía discursiva en la Argentina contemporánea (2001-2015). El estudio de la retórica presidencial resulta, en esta dirección, de especial importancia para comprender los mecanismos a través de los cuales una fuerza, en este caso "Cambiemos", se constituye como espacio discursivo en la Argentina contemporánea, desplegando una hermenéutica histórica que procura organizar retrospectiva y prospectivamente la coyuntura en la que apuesta a intervenir. Nuestro foco estuvo en la descripción de la retórica fundacional del DIM; nos preguntamos cómo Macri procuró performar colectivos políticos por el arte del discurso, cómo intentó volver inteligible la historia reciente a partir de esquemas narrativos que no tuvieron otro fin que el de producir coherencia en hechos diversos y a menudo contradictorios.

El artículo estuvo dividido en cuatro partes. La primera estuvo destinada a describir las características del discurso inaugural como género, con el fin de avanzar luego en los meandros de la alocución del presidente Macri. La segunda parte, la más extensa, presentó un análisis de los principales clivajes del DIM, entendidos como procedimientos orientados a generar una frontera con el pasado reciente y a abrir un horizonte de gestión. 


\section{Conexão Letras}

Mencionamos tres: verdad / mentira, líder / equipo, unión / enfrentamiento, y demostramos cómo se articulaban en un clivaje superior: el de la Argentina del siglo XXI versus la Argentina del pasado. La tercera sección presentó mayormente el análisis de la dimensión programática del DIM, tomando los tres ejes que el propio orador manifestó como centrales: pobreza cero, vencer al narcotráfico y unión de los argentinos. Entramado en buena medida con los clivajes antes trabajados, intentamos demostrar el peso de la unión como núcleo irradiante de la pieza oratoria. El tramo final del artículo estuvo dedicado a la peroratio del DIM, con el fin de exponer las dos operaciones discursivas que daban cierre a la pieza: la recapitulación del mensaje central del DIM y la puesta en escena del ethos del orador como garante del proyecto.

Hoy día, Cambiemos-Pro presenta sus credenciales de gestión en las antípodas de las que trece años antes habían configurado el espacio discursivo del kirchnerismo, el partido de gobierno más prolongado en la historia moderna argentina. El kirchnerismo entró al siglo XXI con las ropas de generaciones pasadas, haciendo de un conjunto de símbolos, marcas y valores generacionales su signo fundacional de "una nueva Argentina". "Cambiemos" apuesta a construir "la Argentina del siglo XXI" con una vuelta de página voraz, en la que el pasado no parece tener mucho que ofrecer, mientras que el futuro es una tentación acelerada y siempre diferida.

El presidente Macri se dirige en el DIM a todos los argentinos bajo el espíritu de celebración de una nación libre, plural y unida en su diversidad. Desde el punto de vista pragmático, al presentar a la Argentina como un país fuertemente cohesionado en sus objetivos y deseos, elabora discursivamente una imagen de nación que no resulta acorde con la realidad, pero que se ajusta, sin duda, a los propósitos y las metas de su gobierno. Ninguna pregunta es quizás tan importante en la Argentina actual como saber hasta qué punto el horizonte desplegado por el DIM constituye un mundo de pertenencia o aspiraciones de las mayorías y hasta qué punto estas aspiraciones no resultan contradictorias con la idea de un país libre, plural e igualitario; un país verdaderamente moderno.

\section{Referencias}

ABOY CARLÉS, Gerardo. Las dos fronteras de la democracia argentina: la reformulación de las identidades políticas de Alfonsín a Menem. Rosario: Homo Sapiens, 2001.

ALTHUSSER, Louis. Ideología y aparatos ideológicos del Estado. Freud y Lacan. Buenos Aires: Nueva Visión, 1988.

ÁLVAREZ, Alejandra; CHUMACEIRO, Irma. El discurso de investidura en la reelección de Uribe y de Chávez. Forma y función, v. 22, n. 2, 2009, p. 13-42.

AMOSSY, Ruth. Entre logos y pathos: las figuras. In: . L'argumentation dans la langue. París: Nathan, 2000.

ANDERSON, Dana. Identity's Strategy: Rhetorical Selves in Conversion. Columbia: University of South Carolina Press, 2007.

ANGENOT, Marc. 1889: Un état du discours social. Montréal: Éditions du Préambule, 1989.

2008.

Dialogue des sourds. Traité de rhétorique antilogique. París: Mille et une Nuits,

. El discurso social. Buenos Aires: Siglo XXI, 2010. 
ARISTÓTELES. El arte de la retórica. Buenos Aires: Eudeba, 2005. Trad. E. Igancio Granero.

BARTHES, Roland. Mitologías. Buenos Aires: Siglo XXI, 2005.

BRUNER, M. Lane. Strategies of Remembrance. The rhetorical dimensions of National Identity. Columbia: University of South Carolina Press, 2002.

BURKE, Kenneth. A rhetoric of motives. Los Angeles: University of California Press, 1969.

CASSIN, Barbara. El efecto sofístico. México: Fondo de Cultura Económico, 2008.

CHARLAND, Maurice. Constitutive Rhetoric. Quarterly Journal of Speech, v. 73, n. 2, 1986, p. 133-150.

CHUMACEIRO, Irma; GALUCCI, Ma. José. La noción de democracia en los

discursos de toma de posesión de Hugo Chávez y Álvaro Uribe. Actas del VII Congreso

Latinoamericano de Estudios del Discurso ALED, Bogotá, 2007, p. 98-107.

DAGATTI, Mariano. Volver al futuro. Las refundaciones discursivas en la Argentina contemporánea (2001-2015). Pensamientos al margen, n. 6, 2017a, p. 47-72.

. Las emociones políticas. Un modelo discursivo de estudio. Rétor, v. 7, n. 1,

2017b, p. 40-72.

DAYAN, Daniel; KATZ, Elihu. Media Events: the live broadcasting of history. Boston:

Harvard University Press, 1992.

EAGLETON, Terry. Cultura. Buenos Aires: Taurus, 2017.

FAIRCLOUGH, Norman. El lenguaje del nuevo capitalismo. In: PARDO, María Laura; NOBLIA, María Valentina (Ed.). Globalización y nuevas tecnologías. Buenos Aires:

Biblos, 2000.

KORHS CAMPBELL, Karlyn; HALL JAMIESON, Kathleen. Presidents Creating the Presidency. Deeds Done in Words. Chicago: University of Chicago Press, 2008.

LÓPEZ EIRE, Antonio. Poéticas y Retóricas griegas. Madrid: Síntesis, 2002.

. Sobre el carácter retórico del lenguaje y de cómo los antiguos griegos lo descubrieron. México: UNAM, 2005a.

. La naturaleza retórica del lenguaje. Logo, Revista de Retórica y teoría de la comunicación, n. 8/9, 2005b, p. 5-24.

MAINGUENEAU, Dominique. Sémantirque de la polémique. Laussane: L’Age d'Homme, 1983.

. Problèmes d'ethos. Pratiques, n. 113-114, 2002, p. 55-67.

MARTÍN ZORRAQUINO, Ma. Antonia; PORTOLÉS, José. Los marcadores del discurso. In: BOSQUE, Ignacio; DEMONTE, Violeta (Ed.). Gramática descriptiva de la lengua española. Madrid: Espasa Calpe, 1999, p. 4051-4212.

MILLER, Jacques-Alain; MILNER, Jean-Claude. ¿Desea usted ser evaluado? Málaga: Miguel Gómez Ediciones, 2004.

MORRESI, Sergio. "Acá somos todos democráticos": el PRO y las relaciones entre la derecha y la democracia en Argentina. In: VOMMARO, Gabriel; MORRESI, Sergio (Comp.). Hagamos equipo. PRO y la construcción de la nueva derecha en Argentina. Buenos Aires: UNGS, 2015, p. 163-201.

PERNOT, Laurent. La retórica en Grecia y Roma. México: UNAM, 2013.

VERÓN, Eliseo. La palabra adversativa. Observaciones sobre la enunciación política. In: VERÓN, Eliseo et al. (Ed.). El discurso político. Lenguajes y acontecimientos.

Buenos Aires: Hachette, 1987, p. 11-26.

VITALE, Ma. Alejandra. Êthos y legitimidad política en los discursos de asunción de la presidente argentina Cristina Fernández de Kirchner. Ícono 14, v. 11, n. 1, 2013, p. 5-25. 


\section{Conexão Letras}

. Ethos femenino en los discursos de asunción de las primeras mujeres

presidentes de América del Sur: Michelle Bachelet, Cristina Fernández de Kirchner y Dilma Rousseff. Anclajes, v.18, n.1, 2014, p. 61-82.

VITALE, Ma. Alejandra; DAGATTI, Mariano. La constitución de la Argentina democrática en el discurso de asunción presidencial de Raúl Alfonsín. Hallazgos, v. 13, n. 26, 2016, p. 65-91.

VOMMARO, Gabriel. Contribución a una sociología política de los partidos. Los mundos sociales de pertenencia y las generaciones políticas de PRO. In: VOMMARO, Gabriel; MORRESI, Sergio. Hagamos equipo. PRO y la construcción de la nueva derecha en Argentina. Buenos Aires: UNGS, 2015, p. 111-161.

VOMMARO, Gabriel; MORRESI, Sergio. Hagamos equipo. PRO y la construcción de la nueva derecha en Argentina. Buenos Aires: UNGS, 2015.

. "La Ciudad nos une". La construcción de PRO en el espacio político argentino.

In:__. Hagamos equipo. PRO y la construcción de la nueva derecha en Argentina.

Buenos Aires: UNGS, 2015, p. 29-70.

VOMMARO, Gabriel; MORRESI, Sergio; BELLOTTI, Alejandro. Mundo Pro.

Anatomía de un partido fabricado para ganar. Buenos Aires: Planeta, 2015.

Recebido em: 03/10/2017 Aceito em: 11/10/2017 